\title{
The lipid-lowering effect of dietary proanthocyanidins in rats involves both chylomicron-rich and VLDL-rich fractions
}

\author{
Helena Quesada, Sabina Díaz, David Pajuelo, Anabel Fernández-Iglesias, Santiago Garcia-Vallvé, \\ Gerard Pujadas, M. Josepa Salvadó, Lluis Arola and Cinta Bladé* \\ Departament de Bioquímica i Biotecnologia, Universitat Rovira i Virgili, Campus Sescel.lades s/n, 43007 Tarragona, Spain
}

(Submitted 6 May 2011 - Final revision received 20 July 2011 - Accepted 8 September 2011 - First published online 20 October 2011)

\begin{abstract}
Proanthocyanidins have been shown to improve postprandial hypertriacylglycerolaemia. The present study aims to determine the actual contribution of chylomicrons (CM) and VLDL in the hypotriacylglycerolaemic action of grape seed proanthocyanidin extract (GSPE) in the postprandial state and to characterise the mechanisms by which the GSPE treatment reduces TAG-rich lipoproteins in vivo. A plasma lipid tolerance test was performed on rats fasted for $14 \mathrm{~h}$ and orally loaded with lard containing either GSPE or not. GSPE (250 mg/kg body weight) markedly blocked the increase in plasma TAG induced by lard, with a statistically significant reduction of $22 \%$ in the area under the curve. The VLDL-rich fraction was the major contributor (72\%) after $1 \mathrm{~h}$, whereas the CM-rich fraction was the major contributor (85\%) after $3 \mathrm{~h}$. At 5 and $7 \mathrm{~h}$ after treatment, CM-rich and VLDL-rich fractions showed a similar influence. Plasma post-heparin lipoprotein lipase (LPL) activity and LPL mRNA levels in white adipose tissue and muscle were not affected by GSPE. On the contrary, GSPE treatment significantly repressed (30\%) the secretion of VLDL-TAG. In the liver, GSPE treatment induced different effects on the expression of acyl-coenzyme A synthetase long-chain family member 1, Apoc3 and 3-hydroxy-3-methylglutaryl-coenzyme A reductase at $1 \mathrm{~h}$ and $\mathrm{Cd} 36$ at $5 \mathrm{~h}$, compared to those induced by lard. Furthermore, GSPE treatment significantly increased the activity of carnitine palmitoyltransferase $1 \mathrm{a}$ at $1 \mathrm{~h}$. In conclusion, both CM-rich and VLDL-rich fractions contributed to the hypotriacylglycerolaemic action of GSPE, but their influence depended on time. GSPE induces hypotriacylglycerolaemic actions by repressing lipoprotein secretion and not by increasing LPL activity.
\end{abstract}

Key words: Carnitine palmitoyltransferase 1a: Fatty acids: Flavonoids: Lipoprotein lipase: TAG

Dyslipidaemia is one of the major determinants of the development of $\mathrm{CVD}^{(1,2)}$. Postprandial lipaemia has emerged as a key contributor to the risk and progression of CVD. Elevated levels of non-fasting TAG are strongly associated with increased risk of myocardial infarction, ischaemic stroke and early death ${ }^{(3)}$.

Proanthocyanidins (PA), the most abundant polyphenols in human diets, have been shown to improve postprandial hypertriacylglycerolaemia in animal models ${ }^{(4)}$, and the ingestion of PA-rich food, such as red wine, has been shown to decrease plasma lipids in human subjects ${ }^{(5)}$. The hypolipidaemic action of grape seed proanthocyanidin extract (GSPE) is attributable to a reduction in plasma levels of TAG-rich lipoproteins and to an improvement of the serum cholesterol profile, both in normolipidaemic ${ }^{(6)}$ and dyslipidaemic rats ${ }^{(7)}$. Additionally, the simultaneous ingestion of apple PA with fat inhibits the increase in plasma TAG levels induced by fat ingestion in mice and human subjects ${ }^{(8)}$.
Plasma TAG levels are the result of the balance between TAG-rich lipoprotein secretion by the intestine and liver and its uptake by the extrahepatic tissues through lipoprotein lipase (LPL). TAG-rich lipoproteins in plasma originate in either the liver (VLDL) or the intestine (chylomicrons, CM). The hypotriacylglycerolaemic effect of PA has been attributed to an inhibition of dietary lipid absorption associated with a reduction in $\mathrm{CM}$ secretion by enterocytes ${ }^{(8,9)}$ as well as a decrease in VLDL secretion by the liver ${ }^{(7,10-12)}$ in a range of different studies. Nevertheless, the real contribution of CM and VLDL secretion and LPL activity to the hypotriacylglycerolaemic action of GSPE has never been studied. Thus, the aim of the present study was to determine the contribution of CM and VLDL in the hypotriacylglycerolaemic action of GSPE in the postprandial state and to characterise the principal mechanisms by which GSPE treatment reduces TAG-rich lipoprotein levels.

Abbreviations: Acsl1, acyl-coenzyme A synthetase long-chain family member 1; CM, chylomicron; CoA, coenzyme A; CPT1a, carnitine palmitoyltransferase 1a; Dgat, diacylglycerol O-acyltransferase; FA, fatty acid; GSPE, grape seed proanthocyanidin extract; Hmgcr, 3-hydroxy-3-methylglutaryl-coenzyme A reductase; LPL, lipoprotein lipase; Mttp, microsomal TAG transfer protein; PA, proanthocyanidin; SREBP, sterol regulatory element-binding protein. 


\section{Materials and methods}

\section{Proanthocyanidin extract}

The PA extract (GSPE) contained monomeric (21.3\%), dimeric $(17 \cdot 4 \%)$, trimeric $(16 \cdot 3 \%)$, tetrameric $(13.3 \%)$ and oligomeric (5-13 units; $31 \cdot 7 \%)$ PA.

\section{Animals}

Male Wistar rats that weighed $350 \mathrm{~g}$ were purchased from Charles River (Barcelona, Spain). All experiments were conducted in conformity with the Public Health Service Policy on Humane Care and Use of Laboratory Animals policy, and the studies were approved by the Animal Ethics Committee of our university. The animals were housed in animal quarters at $22^{\circ} \mathrm{C}$ under a $12 \mathrm{~h}$ light $-12 \mathrm{~h}$ dark cycle (light from 08.00 to 20.00 hours) and were provided standard chow (Panlab, Barcelona, Spain) and water ad libitum.

\section{Plasma lipid tolerance test and measurement of plasma lipid levels}

For the lipid tolerance test, rats were deprived of food for $14 \mathrm{~h}$ before the experiment. Lard oil $(2.5 \mathrm{ml} / \mathrm{kg}$ of body weight) with or without GSPE ( $250 \mathrm{mg} / \mathrm{kg}$ of body weight) was administered orally at $9 \mathrm{~h}$. For blood chemical analyses, aliquots from the tail vein were collected into capillary tubes with EDTA after 1, 3, 5 and $7 \mathrm{~h}$ of treatment. TAG and cholesterol levels were determined using an enzymatic colorimetric kit (QCA, Barcelona, Spain). NEFA levels were determined using the Wako assay kit (Wako Chemicals $\mathrm{GmbH}$, Neuss, Germany). 3-Hydroxy-butyrate was analysed using an enzymatic kit (Ben S.r.l., Milano, Italy).

\section{Lipoprotein fractionation}

Lipoprotein fractions were prepared from plasma samples by means of density gradient ultracentrifugation ${ }^{(13,14)}$. A total volume of $2 \mathrm{ml}$ was put in the bottom of a $6.5 \mathrm{ml}$ polyallomer ultracentrifuge tube (Beckman, Brea, CA, USA). Then, $3 \mathrm{ml}$ of $1.006 \mathrm{~g} / \mathrm{ml}$ density solution was added, and the sample was centrifuged in a 45.6 Kontor rotor. CM was subfractionated by a $30 \mathrm{~min}$ centrifugation at $16000 \mathrm{rpm}$, and VLDL was subfractionated by a $16 \mathrm{~h}$ centrifugation at $37000 \mathrm{rpm}$. After each centrifugation step, $2 \mathrm{ml}$ of the solution at the top of the gradient, which contained the respective lipoprotein subclass, was aspirated and $2 \mathrm{ml}$ of density solution was used to refill the tube before the next run.

The TAG content was determined using an enzymatic colorimetric kit (QCA) in both lipoprotein fractions.

\section{VLDL-TAG secretion assay}

Rats were fasted for $3 \mathrm{~h}$ and then fed with an oral administration of GSPE $(250 \mathrm{mg} / \mathrm{kg}$ of body weight) in aqueous solution (treated group) or an oral administration of the vehicle (tap water; control group). The duration of treatment was 2 h. Rats were injected with $500 \mathrm{mg} / \mathrm{kg}$ Triton WR 1339
(Sigma-Aldrich, St Louis, MO, USA) into the tail vein to inhibit plasma VLDL-TAG hydrolysis and clearance ${ }^{(15)}$. Aliquots of saphenous blood were collected at 0, 10, 20, 30, 40, 50 and 60 min after the Triton WR 1339 injection. Plasma TAG levels were determined using an enzymatic colorimetric kit (QCA) and plotted as a function of time.

\section{Lipoprotein lipase assay}

Rats were deprived of food for $14 \mathrm{~h}$ before the experiment. Lard oil $(2.5 \mathrm{ml} / \mathrm{kg})$ with or without GSPE $(250 \mathrm{mg} / \mathrm{kg}$ of body weight) was administered orally. At $1 \mathrm{~h}$ after the administration, rats were injected with $300 \mathrm{IU}$ heparin/kg body weight intravenously, and saphenous vein blood was sampled 10 min after the heparin infusion. Heparinised plasma was prepared for the determination of LPL activity with the LPL activity kit (Roar Biochemical Inc., New York, NY, USA), as described by the manufacturer.

\section{Carnitine palmitoyltransferase 1 assay}

Rats were initially treated as described in the plasma lipid tolerance test section; later, rats were anaesthetised using ketamine/xylazine and killed by exsanguination. The liver was excised, immediately frozen in liquid $\mathrm{N}_{2}$ and stored at $-80^{\circ} \mathrm{C}$ until the activity assay was performed.

Mitochondria were isolated from the livers, which were homogenated at $4^{\circ} \mathrm{C}$ in a $1: 3$ ratio (w:v) of a buffer containing $250 \mathrm{~mm}$-sucrose, $1 \mathrm{~mm}$-EDTA and $10 \mathrm{~mm}$-Tris- $\mathrm{HCl}$ ( $\mathrm{pH} 7 \cdot 4$ ) with a Teflon/glass homogeniser and then centrifuged at $700 \mathrm{~g}$ for $10 \mathrm{~min}$ at $4^{\circ} \mathrm{C}$. The supernatants were centrifuged at $12000 \mathrm{~g}$ for $10 \mathrm{~min}$ at $4^{\circ} \mathrm{C}$. The resulting pellet containing the purified mitochondria was resuspended in $500 \mu \mathrm{l}$ of a buffer with $70 \mathrm{~mm}$-sucrose, $220 \mathrm{~mm}$-mannitol, 2 mM-HEPES

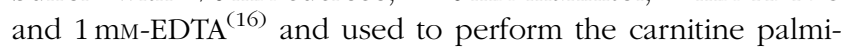
toyltransferase (CPT) 1a assay. Bradford reagent (SigmaAldrich) was used to determine the mitochondrial protein content.

CPT-1 activity was assessed as described by Bieber et al. ${ }^{(17)}$. Assays were performed in triplicate, and $13 \mu$ l of the mitochondrial protein solution was transferred into the assay buffer (116 mm-Tris-HCl, 0.09\% Triton X-100, 1.1 mm-EDTA, 0.035 mm-palmitoyl-coenzyme A (CoA) and $0.12 \mathrm{~mm}-5$, $5^{\prime}$-dithiobis-2-nitrobenzoic acid $(\mathrm{pH} 8.0)$ ) and incubated for $3 \mathrm{~min}$ at $20^{\circ} \mathrm{C}$. Absorbance was then measured at $412 \mathrm{~nm}$. The results are expressed in nmol CoA formed/mg protein per min.

\section{Gene expression analysis}

Rats were initially treated as described in the plasma lipid tolerance test section; later, rats were anaesthetised using ketamine/xylazine and killed by exsanguination. The first $30 \mathrm{~cm}$ of the intestinal mucosa, liver, leg muscle and visceral white adipose tissue was excised and immediately frozen until RNA extraction. Total RNA was isolated using an RNeasy Mini kit (Qiagen, Hilden, Germany) according to the manufacturer's instructions. Complementary DNA was synthesised 
from $2 \mu \mathrm{g}$ of total RNA with the High Capacity complementary DNA Reverse Transcription Kit (Applied Biosystems, Madrid, Spain).

Changes in mRNA expression of LPL in the muscle and white adipose tissue were measured by quantitative PCR. Quantitative PCR amplification and detection were performed using a specific TaqManR Assay-On-Demand probe (Applied Biosystems; Rn00561482_m1), the TaqMan PCR Core Reagent Kit and the GeneAmpR 5700 Sequence Detection System, as recommended by the manufacturers. Quadruplicated quantifications, performed in singleplex assays, were performed for each complementary DNA. PPIA was used as the reference gene in quantitative PCR (Applied Biosystems; TaqManR Assay-On-Demand probe Rn00690933_m1).

Each complementary DNA sample of the liver and intestine $(100 \mu \mathrm{l})$ was added to an equal volume of $2 \times$ TaqMan Universal PCR Master Mix (Applied Biosystems). After gentle mixing and centrifugation, the mixture was then transferred into a loading port on a low-density array card (TLDA; Applied Biosystems). Each TLDA had eight separated loading ports that feed into forty-eight gene sets. Each $2 \mu \mathrm{l}$ well contained specific user-defined probes capable of detecting a single gene. Each set of forty-eight genes also contained PPIA as a housekeeping gene. The array was centrifuged twice for $1 \mathrm{~min}$, each at $1200 \mathrm{rpm}$, to distribute the samples from the loading port into each well. The card was then sealed, and PCR amplification was performed using an Applied Biosystems Prism 7900HT sequence detection system. Thermal cycling conditions were as follows: $2 \mathrm{~min}$ at $50^{\circ} \mathrm{C}, 10 \mathrm{~min}$ at $94.5^{\circ} \mathrm{C}$, $30 \mathrm{~s}$ at $97^{\circ} \mathrm{C}$ and $1 \mathrm{~min}$ at $59 \cdot 7^{\circ} \mathrm{C}$ for forty cycles ${ }^{(18)}$.

\section{Statistical analysis}

Results are reported as mean values with their standard errors of ten animals in the case of plasma TAG, three animals for RNA levels and five animals for other analyses. Group mean values were compared with an independent sample Student's $t$ test, except for those of gene expression, which were compared with one-way ANOVA $(P \leq 0.05)$ using SPSS software (SPSS version 17.0; IBM, New York, NY, USA).

\section{Results}

Grape seed proanthocyanidin extract treatment blocked the increase in plasma total TAG by reducing VLDL-TAG or chylomicron-TAG in a time-dependent manner

In control animals, plasma TAG reached their maximum levels $3 \mathrm{~h}$ after the oral administration of $2.5 \mathrm{ml} / \mathrm{kg}$ of lard oil, after which it decreased (Fig. 1(a)). The administration of GSPE ( $250 \mathrm{mg} / \mathrm{kg}$ body weight) markedly blocked the increase in plasma TAG, with a statistically significant reduction of $22 \%$ in the area under the curve of plasma TAG (Fig. 1(b)). Thus, GSPE treatment improved the tolerance to oral TAG. The hypotriacylglycerolaemic effect of GSPE was extremely rapid (it could be noted after $1.5 \mathrm{~h}$ ), and it was observable until $7 \mathrm{~h}$ after the administration.
To better understand the contribution of CM and VLDL to the hypotriacylglycerolaemic effect of GSPE, we measured the TAG content of the CM-rich and VLDL-rich fractions (Fig. 1(c)). GSPE treatment slightly reduced CM-TAG at all studied time periods, showing its strongest effect after $3 \mathrm{~h}$ of treatment when CM-TAG levels peaked. GSPE treatment rapidly reduced VLDL-TAG levels ( $1 \mathrm{~h}$ after the administration), and the reduction became significant after $7 \mathrm{~h}$. When the same values were expressed as a percentage of the total TAG reduction at each time point (Fig. 1(d)), it was obvious that both lipoproteins have a different pattern. The VLDL-rich fraction was responsible for $72 \%$ of the TAG reduction at $1 \mathrm{~h}$, whereas the CM-rich fraction was responsible for $85 \%$ of the TAG reduction at $3 \mathrm{~h}$. Altogether, these results indicate that both CM and VLDL contributed to the hypotriacylglycerolaemic action of GSPE, but their influence depended on time. The CM-rich fraction was the major contributor after $3 \mathrm{~h}$ of treatment, whereas the VLDL-rich fraction was the major contributor after $1 \mathrm{~h}$. At 5 and $7 \mathrm{~h}$ after treatment, the CM-rich and VLDL-rich fractions showed a similar influence.

Plasma cholesterol levels showed almost the same pattern as plasma TAG levels in animals treated with only lard oil (Fig. 2(a)), but GSPE had no effect on plasma cholesterol content.

GSPE administration significantly reduced NEFA levels (Fig. 2(b)) $5 \mathrm{~h}$ after its administration. 3-Hydroxy-butyrate was significantly reduced $7 \mathrm{~h}$ after the administration of GSPE (Fig. 2(c)).

\section{Grape seed proanthocyanidin extract treatment did not affect TAG clearance}

Plasma TAG levels could be reduced by repressing TAG-rich lipoprotein secretion and/or increasing their uptake by the extrahepatic tissues. Thus, to characterise the mechanism by which GSPE treatment decreases VLDL-TAG and CM-TAG levels, we quantified TAG clearance. As GSPE affected plasma TAG levels rapidly, we measured plasma post-heparin LPL activity after $1 \mathrm{~h}$ of oral administration of lard oil or lard oil + GSPE. As shown in Fig. 3(a), GSPE had no effect on plasma LPL activity. Moreover, no differential expression of LPL was observed as a result of GSPE treatment in white adipose or muscle at 1 or $5 \mathrm{~h}$ after administration (Fig. 3(b) and (c)). Thus, these results strongly suggest that the blockage of the increase in plasma TAG levels induced by GSPE is not attributable to increased TAG clearance.

\section{Grape seed proanthocyanidin extract administration decreased VLDL-TAG secretion}

To assess VLDL-TAG secretion, we injected the rats with Triton WR 1339, which inhibits VLDL-TAG hydrolysis and clearance. VLDL-TAG secretion was measured $2 \mathrm{~h}$ after GSPE administration in rats that were fasted for $5 \mathrm{~h}$ to avoid $\mathrm{CM}$ secretion (Fig. 4). GSPE treatment significantly repressed (30\%) the secretion of VLDL-TAG. As VLDL is mainly secreted by the liver, these results strongly suggest that the decrease in plasma VLDL-TAG levels induced by GSPE is due to 
(a)

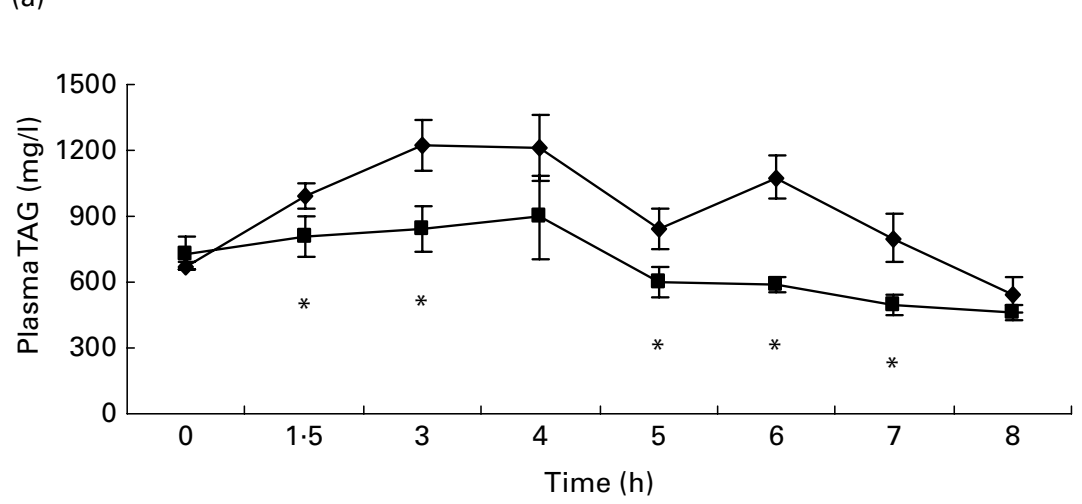

(b)

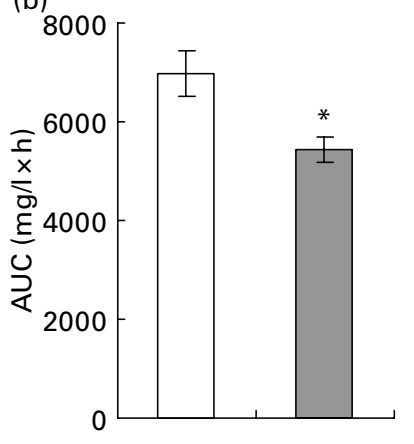

Chylomicron-TAG (mg/l) (c)

(mg/l)
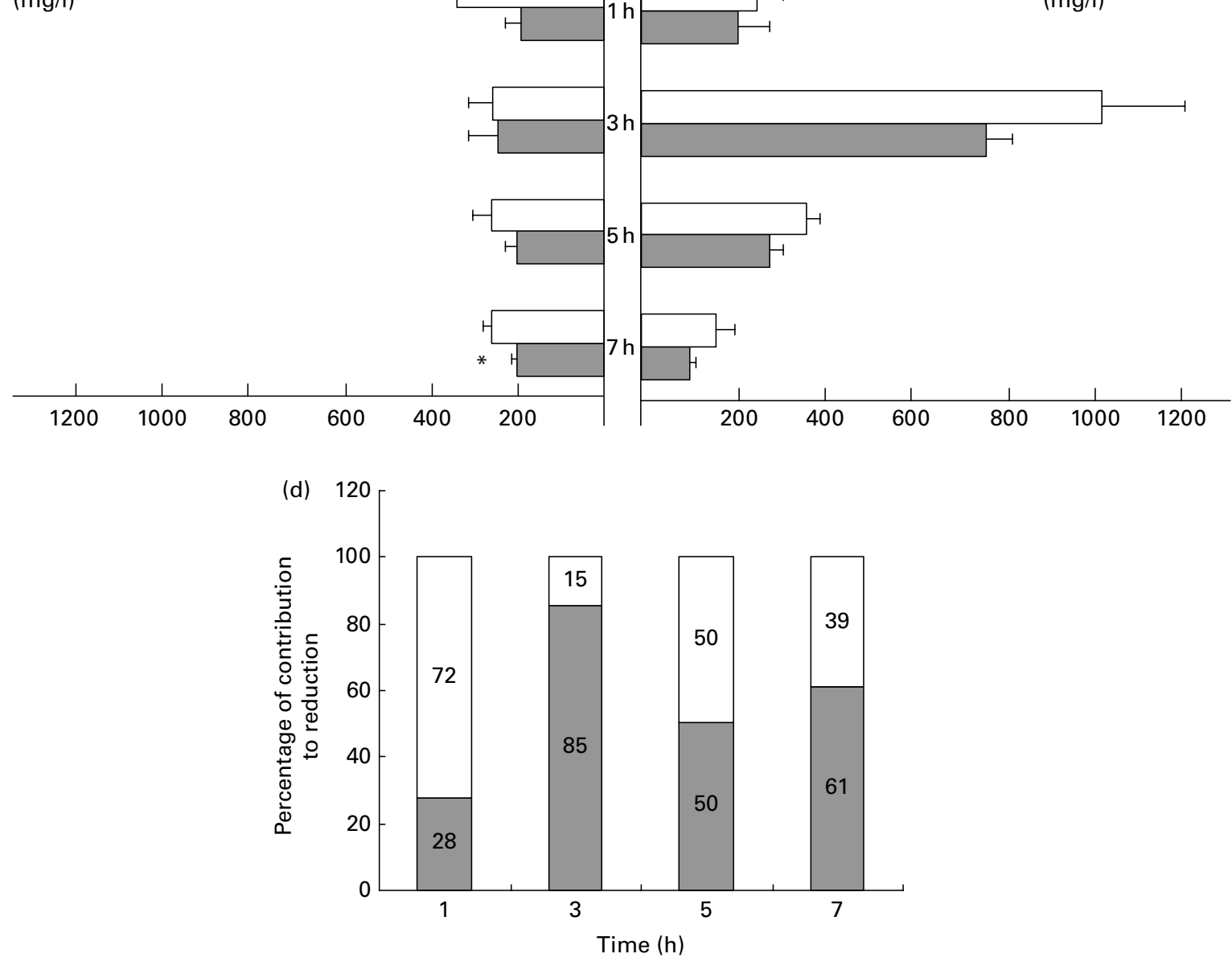

Fig. 1. TAG levels in plasma and TAG content in chylomicron (CM)-rich and VLDL-rich fractions of rats fed on lard oil with or without proanthocyanidins (grape seed proanthocyanidin extract, GSPE). Rats fasted for $14 \mathrm{~h}$ were administered lard oil $(2.5 \mathrm{ml} / \mathrm{kg}$ ) with or without GSPE (250 mg/kg) orally. (a) Plasma TAG were quantified in blood samples of the tail vein before $(0 \mathrm{~h})$ and after 1.5, 3, 4, 5, 6, 7 and $8 \mathrm{~h}$ of the administration. $\downarrow$, Lard; $\mathbf{\square}$, lard $+\mathrm{GSPE}$. (b) The $y$-axis represents the values of the area under the curve. (c) TAG content in CM-rich and VLDL-rich fractions were quantified in plasma from rats killed $1,3,5$ and $7 \mathrm{~h}$ after the administration. $\square$, Lard; $\square$, lard + GSPE. (d) Contribution to the reduction in percentage of VLDL ( $\square$ )-TAG and CM ( $\square$ )-TAG to plasma TAG at each time studied. Values are means with their standard errors represented by vertical or horizontal bars ( $n 10$ for plasma TAG and of $n 5$ for CM and VLDL TAG). ${ }^{*}$ Mean values were significantly different between the lard group and the lard + GSPE group at the same time $(P<0.05$; Student's $t$ test). 
(a)

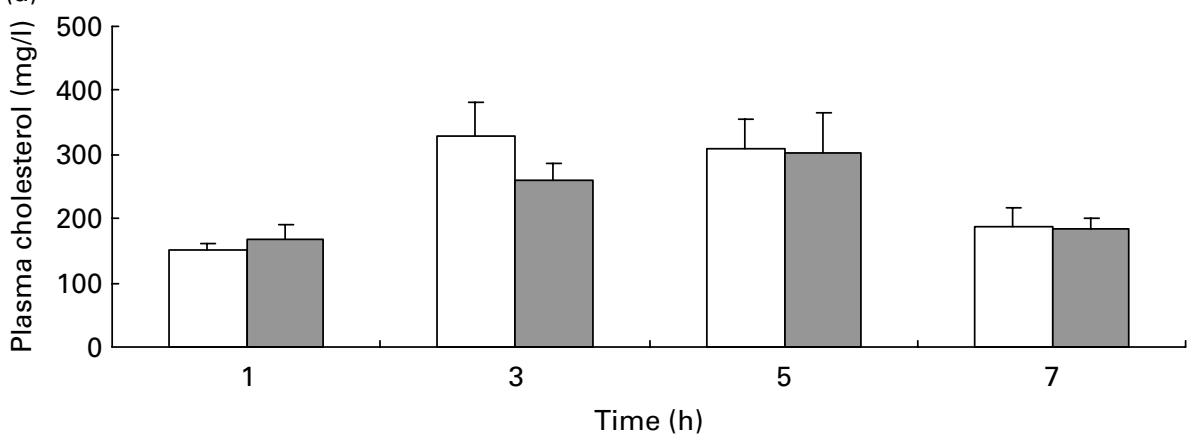

(b)

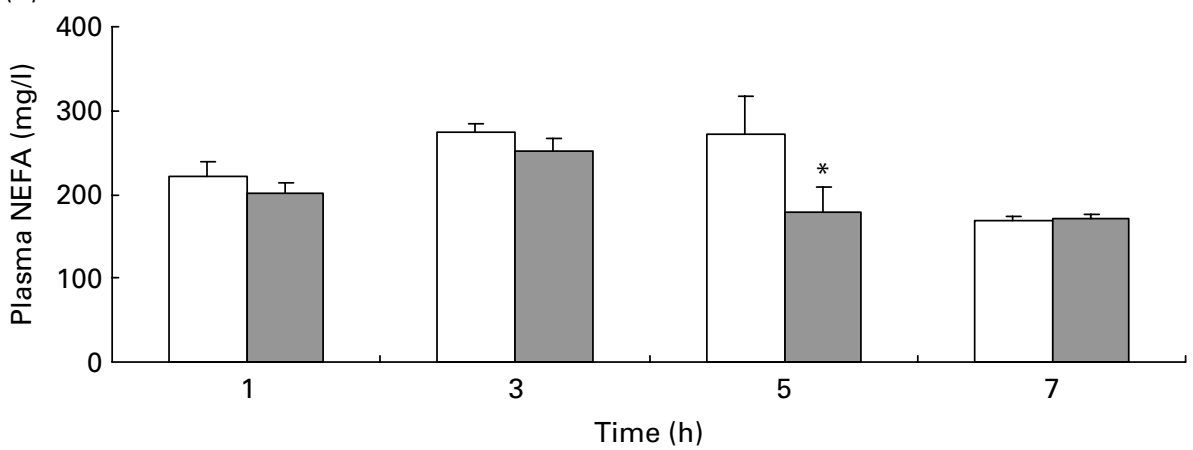

(c)

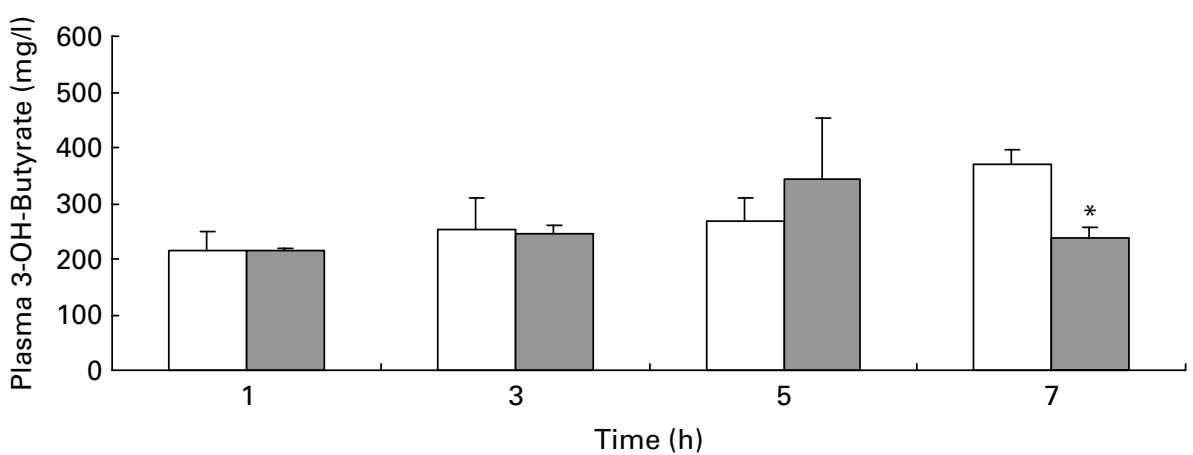

Fig. 2. Plasma levels of NEFA, cholesterol and 3-hydroxy-butyrate (3-OH-butyrate) of rats fed on lard oil with or without proanthocyanidins (grape seed proanthocyanidin extract, GSPE). Rats fasted for $14 \mathrm{~h}$ were administered lard oil ( $\square ; 2.5 \mathrm{ml} / \mathrm{kg}$ ) with or without GSPE ( $\square ; 250 \mathrm{mg} / \mathrm{kg}$ ) orally. (a) Plasma cholesterol, (b) NEFA and (c) 3-OH-butyrate were quantified from the plasma of rats killed 1, 3,5 and $7 \mathrm{~h}$ after the administration. Values are means with their standard errors represented by vertical bars $(n 5)$. ${ }^{*}$ Mean values were significantly different between the lard group and the lard + GSPE group at the same time $(P<0.05$; Student's $t$ test).

GSPE action in the liver, which in turn represses VLDL-TAG secretion.

Grape seed proanthocyanidin extract treatment modulated the expression of some lipid-related genes in the liver but not in the intestine

To determine the molecular mechanisms underlying TAG-rich lipoprotein secretion, we used a TLDA to analyse the differential expression of key genes that control TAG and cholesterol metabolism in the intestine and liver at 0 (before treatment, basal state), 1 and $5 \mathrm{~h}$ after lard oil or lard oil + GSPE administration. We chose the following genes that encode key proteins in lipid pathways: for cholesterol metabolism, the intestinal uptake transporter Niemann-Pick C1-like protein 1
(Npc111), the ATP-binding cassettes implicated in the intestinal and biliary excretion of sterols (Abcg5 and Abcg8), ATP-binding cassette sub-family A member 1 (Abca1), the enzyme controlling cholesterol synthesis 3-hydroxy-3-methylglutaryl-CoA reductase (Hmgcr) and the enzyme acetyl-CoA acetyltransferase 2 (Acat2), which catalyses the conversion of free cholesterol to cholesteryl esters; for fatty acid (FA) metabolism, the FA transporter $\mathrm{CD} 36$, the FA binding protein 1 (Fabp1), the enzyme controlling $\beta$-oxidation carnitine palmitoyltransferase 1a (Cpt1a), the enzyme FA synthase (Fasn), the enzyme controlling the synthesis of unsaturated FA stearoyl-CoA desaturase 1 and the enzyme acyl-CoA synthetase long-chain family member 1 (Acsl1), which catalyses the ligation of long chain FA with CoA to produce long chain acyl-CoA; for TAG synthesis, the $\mathrm{Mg}^{2+}$-dependent PA phosphatase lipin 1 (Lpin1) 
(a)
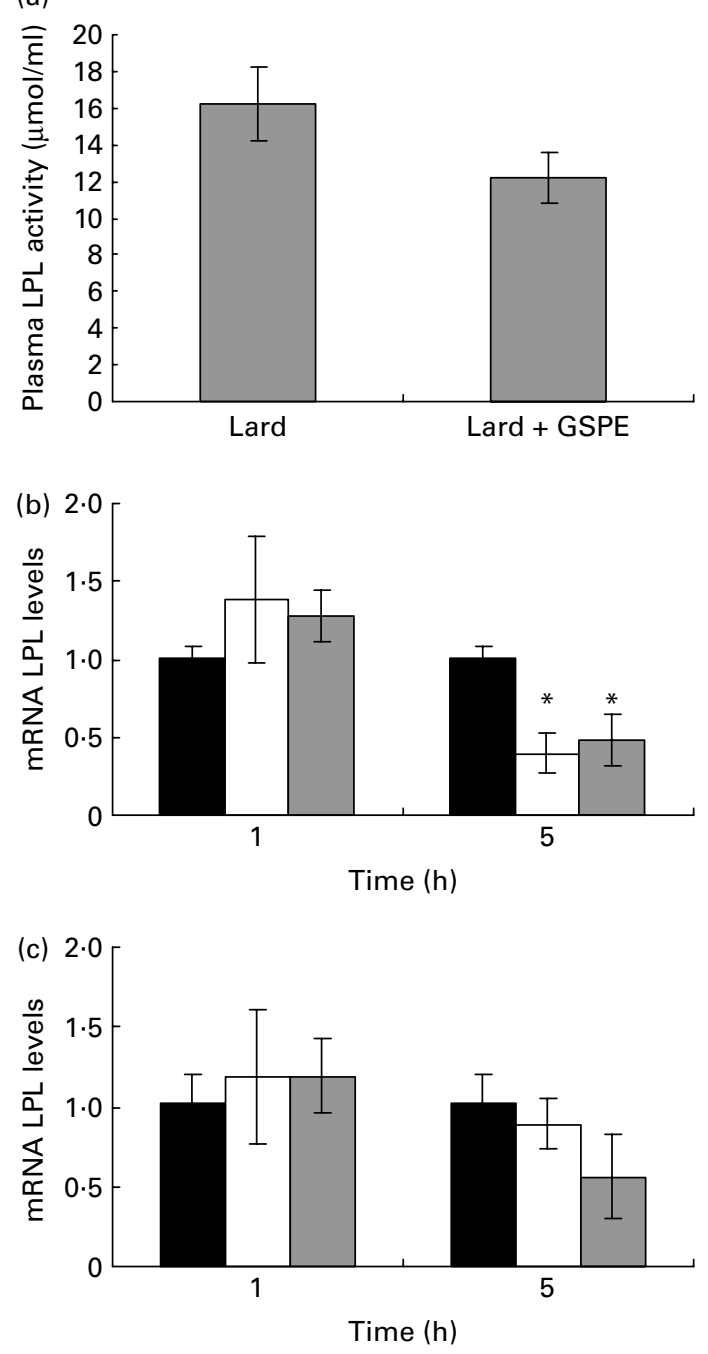

Fig. 3. Post-heparin plasma lipoprotein lipase (LPL) activity and mRNA levels of LPL in white adipose tissue and muscle of rats fed on lard oil with or without proanthocyanidins (grape seed proanthocyanidin extract, GSPE). (a) Post-heparin plasma LPL activity was quantified an hour after the administration of lard oil $(2.5 \mathrm{ml} / \mathrm{kg})$ with or without GSPE $(250 \mathrm{mg} / \mathrm{kg})$ to rats fasted for $14 \mathrm{~h}$ and injected $300 \mathrm{IU}$ heparin/kg body weight intravenously. mRNA levels of LPL in (b) white adipose tissue and (c) muscle were determined 1 and $5 \mathrm{~h}$ after the administration of lard oil $(\square ; 2.5 \mathrm{ml} / \mathrm{kg})$ with or without GSPE $(\square ; 250 \mathrm{mg} / \mathrm{kg}$ ) to rats fasted for $14 \mathrm{~h}$. The basal state $(\boldsymbol{\square} ; 0 \mathrm{~h})$ corresponds to mRNA values before the oral administration. The gene expression values are expressed as fold changes using PPIA expression as the endogenous control. Values are means with their standard errors represented by vertical bars ( $n 3$ for mRNA LPL and $n 5$ for the LPL activity). ${ }^{*}$ Mean values were significantly different between the lard group and the lard + GSPE group at the same time $(P<0.05$; Student's $t$ test).

and the diacylglycerol $O$-acyltransferase homologues 1 and 2 (Dgat1 and Dgat2), which catalyse the final step of TAG synthesis; and for lipoprotein assembling and composition, microsomal TAG transfer protein (Mttp), Apoa5 and Apoc3. We also selected the nuclear receptors farnesoid $\mathrm{X}$ receptor (Fxr) and small heterodimer partner (Shp) and the transcription factor sterol regulatory element-binding protein (Srebp)$1 \mathrm{c}$, because they govern the expression of key lipid metabolism genes in the intestine and the liver and are involved in the molecular mechanism used by GSPE in the liver ${ }^{(10,11)}$.
In the intestine (Table 1), the ingestion of lard induced a generalised repression of genes related to lipid metabolism, excluding acetyl-CoA acetyltransferase 2, which was overexpressed. GSPE did not induce different effects from those induced by lard oil alone on the genes studied at both times, except Cpt1a, which was repressed $5 \mathrm{~h}$ post-administration.

Table 2 shows the mRNA levels of genes related to lipid metabolism in the liver, except for those of Cpt1a, which have been included in Table 3. At $1 \mathrm{~h}$ after the administration of lard oil, the livers showed significant overexpression of lipin 1 in conjunction with significant repression of Acsl1 and Dgat1 relative to their basal levels. The livers of rats treated with GSPE presented the same expression pattern for lipin 1 and Dgat 1 at the $1 \mathrm{~h}$ mark. On the other hand, GSPE treatment induced different effects on the expression Acsl1, Apoc3 and Hmgcr compared to those induced by lard oil treatment. After GSPE treatment, Acsl1 was not repressed, Apoc3 was repressed and $\mathrm{Hmgcr}$ was overexpressed relative to their basal levels.

However, $5 \mathrm{~h}$ after the administration of lard oil, the livers showed significant repression of Dgat1, Acsl1, Mttp and Shp in conjunction with significant overexpression of $\mathrm{Cd} 36$ relative to their basal levels. The livers of rats treated with GSPE presented the same expression pattern for Dgat1, Acsl1, Mttp and Shp after $5 \mathrm{~h}$. Nevertheless, GSPE treatment induced different effects from those induced by lard oil treatment on the expression of $\mathrm{Cd} 36$

\section{Grape seed proanthocyanidin extract treatment channelled fatty acid into $\beta$-oxidation in the liver immediately (1 h)}

The relationship between FA oxidation and esterification in the liver has been described as a key factor in the regulation of VLDL synthesis ${ }^{(19)}$. As enzymes related to FA esterification (Dgat1 and 2) were not differentially expressed in response

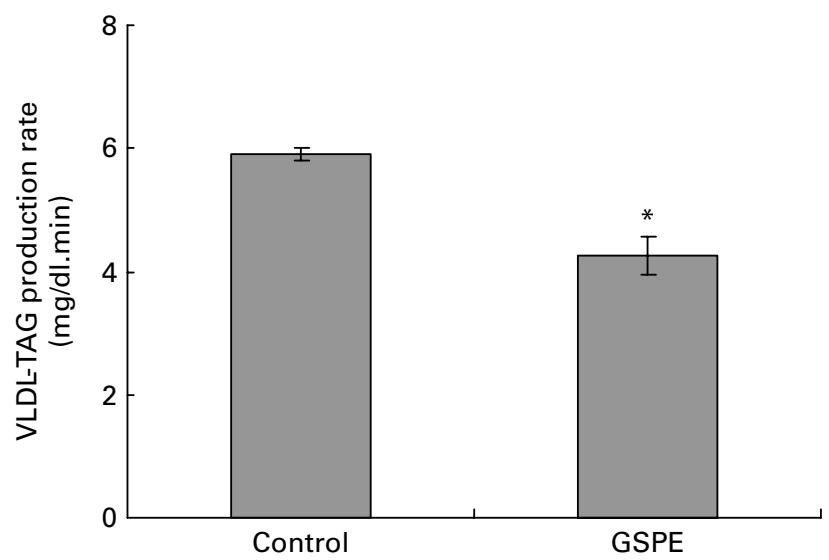

Fig. 4. VLDL-TAG secretion in rats treated with proanthocyanidins (grape seed proanthocyanidin extract, GSPE). VLDL-TAG secretion was evaluated in rats fasted for $5 \mathrm{~h}$. Rats were administered GSPE $(250 \mathrm{mg} / \mathrm{kg})$ or water orally and injected with $500 \mathrm{mg} / \mathrm{kg}$ of Triton WR 1339 through the tail vein to inhibit plasma TAG clearance. Aliquots of saphenous blood were collected at $0,10,20,30,40,50$ and 60 min after Triton WR 1339 injection. Values are means with their standard errors represented by vertical bars $(n 5)$. * Mean values were significantly different $(P<0.05$; Student's $t$ test). 
Table 1. mRNA levels of genes related to lipid metabolism in the intestinal mucosa of rats fed on lard oil with or without proanthocyanidins (grape seed proanthocyanidin extract; GSPE) at $1 \mathrm{~h}$ and $5 \mathrm{~h} \S$ (Mean values with their standard errors for three rats)

\begin{tabular}{|c|c|c|c|c|c|c|c|c|c|c|}
\hline \multirow[b]{2}{*}{ Gene } & \multicolumn{2}{|c|}{ Basal $(0 h)$} & \multicolumn{2}{|c|}{ Lard (1 h) } & \multicolumn{2}{|c|}{$\begin{array}{c}\text { Lard + GSPE } \\
(1 \mathrm{~h})\end{array}$} & \multicolumn{2}{|c|}{ Lard (5h) } & \multicolumn{2}{|c|}{$\begin{array}{c}\text { Lard }+ \text { GSPE } \\
(5 \mathrm{~h})\end{array}$} \\
\hline & Mean & SEM & Mean & SEM & Mean & SEM & Mean & SEM & Mean & $\mathrm{SE}$ \\
\hline Npc1/1 & $1 \cdot 20$ & 0.40 & 0.40 & 0.17 & 0.45 & 0.20 & $0 \cdot 21^{\star}$ & 0.20 & $0 \cdot 13^{*}$ & \\
\hline Abcg5 & 1.20 & 0.35 & $0.27^{\star}$ & 0.09 & $0.29^{*}$ & 0.12 & $0 \cdot 11^{*}$ & 0.02 & $0.10^{*}$ & \\
\hline Abcg 8 & 1.20 & 0.39 & $0.20^{*}$ & 0.05 & $0.22^{*}$ & 0.08 & $0 \cdot 10^{*}$ & 0.03 & $0.08^{\star}$ & \\
\hline Abca1 & $1 \cdot 21$ & 0.34 & $0.39^{\star}$ & 0.10 & $0.47^{\star}$ & 0.02 & $0.21^{*}$ & 0.01 & $0.34^{*}$ & \\
\hline Acat2 & 1.00 & 0.04 & $1.23 \dagger$ & 0.08 & $1.20 \dagger$ & 0.04 & $1.51 \dagger$ & 0.15 & $1.62 \dagger$ & \\
\hline $\mathrm{Hmgcr}$ & $1 \cdot 10$ & 0.25 & $1 \cdot 14$ & 0.52 & 1.39 & 0.22 & 0.65 & 0.21 & 0.71 & \\
\hline Cd36 & 1.12 & 0.30 & $0.21^{*}$ & 0.09 & $0.25^{\star}$ & 0.10 & $0 \cdot 10^{*}$ & 0.02 & $0.07^{*}$ & \\
\hline Fabp1 & 1.20 & 0.35 & 0.51 & 0.16 & 0.50 & 0.17 & $0.35^{\star}$ & $0 \cdot 10$ & $0.22^{\star}$ & \\
\hline Cpt1a & 1.03 & 0.13 & 0.71 & 0.21 & 0.60 & 0.14 & 0.57 & 0.22 & $0.38^{*} \ddagger$ & \\
\hline Fasn & 1.11 & 0.28 & 0.34 & 0.11 & 0.45 & 0.26 & $0 \cdot 16^{*}$ & 0.05 & $0.32^{*}$ & \\
\hline$A c s / 1$ & $1 \cdot 13$ & 0.31 & $0.30^{*}$ & 0.08 & $0.40^{*}$ & 0.12 & $0 \cdot 26^{\star}$ & 0.03 & $0.24^{*}$ & \\
\hline Dgat1 & 1.12 & 0.29 & 0.35 & 0.13 & 0.40 & 0.15 & $0 \cdot 18^{*}$ & 0.06 & $0.13^{*}$ & \\
\hline Dgat2 & 1.27 & 0.46 & 0.30 & 0.09 & 0.30 & 0.11 & 0.44 & 0.20 & 0.28 & \\
\hline Lpin1 & 1.22 & 0.40 & 0.50 & 0.07 & 0.54 & 0.23 & $0 \cdot 30$ & 0.07 & 0.50 & \\
\hline Mttp & 1.10 & 0.26 & 0.55 & 0.17 & 0.62 & 0.25 & 0.55 & 0.17 & 0.33 & \\
\hline Apoa5 & 1.05 & 0.20 & 0.79 & 0.50 & $1 \cdot 31$ & 0.89 & $0.24^{*}$ & 0.07 & $0.20^{*}$ & \\
\hline Apoc3 & $1 \cdot 10$ & 0.25 & 0.31 & 0.12 & 0.38 & 0.17 & $0 \cdot 16^{*}$ & 0.06 & $0 \cdot 11^{*}$ & \\
\hline Nr1h4 (Fxr) & 1.02 & 0.10 & 1.40 & 0.25 & 1.43 & 0.33 & $0.63^{*}$ & 0.16 & $0.46^{\star}$ & \\
\hline Rxra & $1 \cdot 13$ & 0.30 & 0.39 & 0.15 & 0.53 & 0.18 & $0.22^{*}$ & 0.05 & $0.20^{\star}$ & \\
\hline NrOb2 (Shp) & $1 \cdot 10$ & 0.22 & $0.42^{*}$ & 0.12 & $0.40^{*}$ & 0.14 & $0.28^{*}$ & $0 \cdot 13$ & $0.12^{*}$ & \\
\hline Srebf1 & 1.26 & 0.43 & 0.36 & 0.12 & 0.30 & 0.11 & 0.54 & 0.23 & 0.25 & \\
\hline
\end{tabular}

${ }^{*}$ Mean value was significantly decreased from basal $(P<0.05)$

† Mean value was significantly increased from basal $(P<0.05)$.

$\ddagger$ Mean value was significantly difference $(P<0.05)$ from that of the lard group at $5 \mathrm{~h}(P<0.05 ;$ ANOVA $)$.

$\S$ Rats fasted for $14 \mathrm{~h}$ were administered lard oil $(2.5 \mathrm{ml} / \mathrm{kg})$ with or without GSPE $(250 \mathrm{mg} / \mathrm{kg})$ orally and were killed at $1 \mathrm{~h}$ or $5 \mathrm{~h}$ after the administration. The basal state $(0 \mathrm{~h})$ corresponds to mRNA values before the oral administration. The values are expressed as fold change using PPIA expression as the endogenous control. For gene names, see the 'Grape seed proanthocyanidin extract treatment modulated the expression of some lipid-related genes in the liver but not in the intestine' section.

to GSPE, we performed an in-depth study of the effects of lard oil with or without GSPE on FA oxidation. To the present aim, both the mRNA expression and activity of Cpt1a, which is the rate-limiting enzyme in $\beta$-oxidation, were determined at different time periods post-administration (Table 3). Lard oil administration significantly repressed the expression of Cpt1a and decreased its activity by $60 \%$ at $1 \mathrm{~h}$ after its ingestion. In contrast, when lard oil was administered with GSPE, there was no repression of Cpt1a, and its activity remained high. At $5 \mathrm{~h}$ after the administration, the expression pattern was opposite of that observed after $1 \mathrm{~h}$. Cpt1a expression had recovered in the livers of rats treated with lard oil, whereas in the livers of rats treated with lard oil + GSPE, Cpt1a expression and activity were repressed. These results suggest that GSPE treatment channelled FA into $\beta$-oxidation shortly after treatment initiation.

\section{Discussion}

Several authors have reported the hypotriacylglycerolaemic effects of PA in human subjects and animals (reviewed in Blade et $\left.a l .{ }^{(4)}\right)$. Plasma TAG levels are the result of the balance between the TAG-rich lipoprotein secretion by the intestine and the liver, and its uptake by the extrahepatic tissues through LPL. Therefore, GSPE may reduce plasma TAG levels by acting on the intestine, liver and/or peripheral tissues. However, the exact role of each organ remains unknown. For this reason, the present study intended to quantify the contribution of CM and VLDL production and LPL activity to the hypotriacylglycerolaemic action of PA in vivo. With this aim, we analysed the effects of GSPE on plasma lipids and lipoprotein kinetics during a fed state with a lipid tolerance test ${ }^{(20)}$. To our knowledge, this is the first study performed to measure the contribution of CM and VLDL to hypotriacylglycerolaemia induced by PA or other flavonoids.

The present results show that the oral intake of GSPE significantly blocked the increase in plasma TAG levels induced by lard oil ingestion in control animals. This blockade of plasma TAG has also been described with PA from apples ${ }^{(8)}$ in mice loaded with maize oil, in which the blockade was as rapid as that observed in the present experiment $(1 \mathrm{~h})$. In the present study, the reduction in plasma TAG levels was similar to the reductions observed in male normolipidaemic rats $^{(6)}$ and mice ${ }^{(10,11)}$ after performing acute GSPE treatment and in dyslipidaemic rats $^{(7)}$ after performing chronic GSPE treatment. Thus, the improvement of plasma TAG levels is a generalised effect of PA, as it is observed in different situations and experimental approaches. Consequently, PA-rich foods may alleviate the hypertriacylglycerolaemia associated with the postprandial state and may therefore improve tolerance to dietary lipids.

Both CM-rich and VLDL-rich fractions contributed to the hypotriacylglycerolaemic action of GSPE, but their influence was time dependent. CM-rich fraction was the main 
Table 2. mRNA levels of genes related to lipid metabolism in the liver of rats fed on lard oil with or without proanthocyanidins (grape seed proanthocyanidin extract; GSPE) at $1 \mathrm{~h}$ and $5 \mathrm{~h} \ddagger$ (Mean values with their standard errors for three rats)

\begin{tabular}{|c|c|c|c|c|c|c|c|c|c|c|}
\hline \multirow[b]{2}{*}{ Gene } & \multicolumn{2}{|c|}{ Basal (0h) } & \multicolumn{2}{|c|}{ Lard (1 h) } & \multicolumn{2}{|c|}{$\begin{array}{c}\text { Lard + GSPE } \\
(1 \mathrm{~h})\end{array}$} & \multicolumn{2}{|c|}{ Lard (5h) } & \multicolumn{2}{|c|}{$\begin{array}{c}\text { Lard }+ \text { GSPE } \\
(5 \mathrm{~h})\end{array}$} \\
\hline & Mean & SEM & Mean & SEM & Mean & SEM & Mean & SEM & Mean & SEM \\
\hline Abcg5 & 1.02 & 0.11 & 1.08 & 0.05 & 0.88 & $0 \cdot 10$ & 0.94 & 0.18 & 1.09 & 0.02 \\
\hline Abcg 8 & 1.08 & 0.25 & 1.04 & 0.05 & 0.74 & 0.10 & 0.95 & 0.18 & 1.01 & 0.08 \\
\hline Abca1 & 1.02 & 0.12 & 0.94 & 0.22 & 0.84 & 0.08 & 0.71 & 0.08 & 0.86 & 0.17 \\
\hline Acat2 & 1.00 & 0.04 & 0.95 & $0 \cdot 10$ & 1.02 & 0.08 & 0.87 & 0.09 & 0.70 & 0.07 \\
\hline $\mathrm{Hmgcr}$ & 1.03 & 0.15 & 1.73 & 0.32 & $2.96 \dagger$ & 0.21 & 0.83 & 0.06 & 1.00 & 0.19 \\
\hline Cd36 & 1.01 & 0.09 & $1 \cdot 27$ & 0.15 & 1.28 & 0.18 & $1.34 \dagger$ & 0.06 & 1.05 & 0.10 \\
\hline Fabp1 & 1.00 & 0.05 & $1 \cdot 12$ & 0.10 & $1 \cdot 18$ & 0.04 & 0.83 & 0.07 & 0.88 & 0.08 \\
\hline Cpt1a & 1.03 & 0.14 & $0.66^{*}$ & 0.0 & 0.75 & 0.04 & 0.74 & 0.02 & $0.67^{*}$ & 0.05 \\
\hline Fasn & 1.09 & 0.26 & $2 \cdot 65$ & 1.43 & 0.47 & 0.21 & 0.42 & 0.05 & $0.26^{*}$ & 0.01 \\
\hline Scd1 & 1.09 & 0.28 & 1.95 & 0.44 & 1.68 & 0.61 & $1 \cdot 12$ & 0.04 & 1.43 & 0.28 \\
\hline Acs $/ 1$ & 1.01 & 0.08 & $0.64^{*}$ & 0.05 & 0.86 & 0.03 & $0.74^{\star}$ & 0.07 & $0.69^{*}$ & 0.05 \\
\hline Dgat1 & 1.01 & 0.06 & $0.62^{*}$ & 0.12 & $0.71^{*}$ & 0.08 & $0.51^{*}$ & 0.05 & $0.55^{*}$ & 0.06 \\
\hline Dgat2 & 1.01 & 0.06 & 0.88 & 0.05 & 1.00 & 0.07 & 1.00 & 0.11 & $1 \cdot 15$ & 0.04 \\
\hline Lpin1 & 1.04 & 0.18 & $3.02 \dagger$ & 0.44 & $2.74 \dagger$ & 0.26 & 0.82 & 0.12 & 0.65 & 0.02 \\
\hline Mttp & 1.00 & 0.05 & 0.95 & $0 \cdot 10$ & 0.98 & 0.13 & $0.60^{*}$ & 0.04 & $0.64^{*}$ & 0.04 \\
\hline Apoa5 & 1.00 & 0.03 & 0.89 & 0.08 & 1.03 & 0.01 & 1.06 & 0.13 & 0.93 & 0.06 \\
\hline Apoc3 & 1.01 & 0.07 & 0.80 & 0.08 & $0.75^{\star}$ & 0.06 & 0.87 & 0.09 & 0.81 & 0.04 \\
\hline Nr1h4 (Fxr) & 1.05 & 0.17 & 0.71 & 0.08 & 0.89 & 0.03 & 1.00 & 0.11 & 1.00 & 0.15 \\
\hline Rxra & 1.00 & 0.01 & 0.93 & 0.01 & 0.96 & 0.01 & 0.96 & 0.03 & $1 \cdot 10$ & 0.16 \\
\hline NrOb2 (Shp) & 1.07 & 0.20 & 1.85 & 0.53 & 1.79 & 0.56 & $0.27^{\star}$ & 0.09 & $0.41^{*}$ & 0.07 \\
\hline Srebf1 & 1.02 & 0.13 & 0.85 & 0.28 & 0.75 & 0.17 & 0.97 & 0.17 & 0.67 & 0.19 \\
\hline
\end{tabular}

* Mean value was significantly decreased from basal $(P<0.05)$.

† Mean value was significantly increased from basal $(P<0.05)$.

$\ddagger$ Rats fasted for $14 \mathrm{~h}$ were administered lard oil $(2.5 \mathrm{ml} / \mathrm{kg})$ with or without GSPE $(250 \mathrm{mg} / \mathrm{kg})$ orally and were killed at $1 \mathrm{~h}$ or $5 \mathrm{~h}$ after the administration. The basal state $(0 \mathrm{~h})$ corresponds to mRNA values before the oral administration. The values are expressed as fold change using PPIA expression as the endogenous control. For gene names, see the 'Grape seed proanthocyanidin extract treatment modulated the expression of some lipid-related genes in the liver but not in the intestine' section.

contributor $3 \mathrm{~h}$ post-treatment, whereas VLDL-rich fraction was important $1 \mathrm{~h}$ post-treatment. As GSPE did not increase TAG clearance by extrahepatic tissues, the reductions of CM-TAG and VLDL-TAG levels induced by GSPE could be ascribed to repressed lipoprotein secretion. It is generally assumed that CM predominantly transports exogenously ingested TAG derived from dietary sources, whereas VLDL transports endogenously synthesised lipids ${ }^{(21)}$. Therefore, PA repress the secretion of both synthesised, endogenous TAG and TAG absorbed from the diet.

Several authors have reported that CM and lipid absorption cause the hypolipidaemic actions of PA, but only on the basis of indirect evidence or in vitro experiments ${ }^{(8,9)}$. The expression of the selected genes related to FA and TAG metabolism as well as those of the CM assembly was not modified in the intestinal mucosa at 1 or $5 \mathrm{~h}$ after GSPE administration. Therefore, other genes and/or molecular mechanisms could be involved in this repression, and future studies are warranted.

We did not determine the secretion of CM-TAG. However, TAG secretion associated with VLDL was repressed up to $30 \%$ by GSPE treatment. Thus, the repression of VLDL secretion appears to be an important contributor to the hypotriacylglycerolaemic effect of PA. The liver is the primary organ that secretes $\mathrm{VLDL}^{(22,23)}$. Consequently, regarding the hypotriacylglycerolaemia induced by PA in the postprandial state, the liver is a significant target for GSPE.

The regulation of hepatic VLDL secretion mainly depends on apoB synthesis, MTTP activity and lipid availability ${ }^{(19)}$. The present results suggest that the unavailability of lipids is

Table 3. Carnitine palmitoyl transferase 1 expression and activity in the liver of rats fed on lard oil with or without proanthocyanidins (GSPE)‡ (Mean values with their standard errors for five rats for Cpt1 activity and three rats for Cpt1 mRNA)

\begin{tabular}{|c|c|c|c|c|c|c|c|c|c|c|}
\hline & \multicolumn{2}{|c|}{ Basal $(0 \mathrm{~h})$} & \multicolumn{2}{|c|}{ Lard $(1 \mathrm{~h})$} & \multicolumn{2}{|c|}{$\begin{array}{c}\text { Lard + GSPE } \\
(1 \mathrm{~h})\end{array}$} & \multicolumn{2}{|c|}{ Lard $(5 \mathrm{~h})$} & \multicolumn{2}{|c|}{$\begin{array}{c}\text { Lard + GSPE } \\
(5 \mathrm{~h})\end{array}$} \\
\hline & Mean & SEM & Mean & SEM & Mean & SEM & Mean & SEM & Mean & SEM \\
\hline Cpt1 activity (nmol CoA/mg protein $\times$ min) & $4 \cdot 0$ & 0.8 & 1.6 & 0.5 & $3 \cdot 2^{*}$ & 0.1 & 3.6 & 0.9 & $1.4^{*}$ & 0.3 \\
\hline Cpt1 mRNA (fold change) & 1.03 & 0.14 & $0.66 \dagger$ & 0.05 & 0.75 & 0.04 & 0.74 & 0.02 & $0.67 \dagger$ & 0.05 \\
\hline
\end{tabular}

* Mean value was significantly difference $(P<0.05)$ from that of the lard group at $5 \mathrm{~h}(P<0.05$; Student's $t$ test $)$

† Mean value was significantly decreased from basal $(P<0.05)$.

¥ Rats fasted for $14 \mathrm{~h}$ were administered lard oil $(2.5 \mathrm{ml} / \mathrm{kg})$ with or without GSPE $(250 \mathrm{mg} / \mathrm{kg})$ orally and were killed at $1 \mathrm{~h}$ or $5 \mathrm{~h}$ after the administration. The basal state $(0 \mathrm{~h})$ corresponds to mRNA values before the oral administration. 
the primary cause of the reduction of VLDL-TAG secretion by the liver. Shortly after GSPE administration (1 h), CPT-1a activity and expression remained high, suggesting elevated FA oxidation. A pattern similar to that of CPT-1a was observed for Acsl1 mRNA. Specific ACSL isoforms provide acyl-CoA for particular metabolic pathways ${ }^{(24)}$, and Acsl1 has been reported to have a role in mitochondrial $\beta$-oxidation in knockout models of ACSL1. The relationship between FA oxidation and esterification has been described as a key factor in the regulation of VLDL synthesis ${ }^{(19)}$. Therefore, the increased oxidation of FA induced by GSPE treatment is a potential mechanism by which PA reduce VLDL-TAG secretion shortly after GSPE administration ( $1 \mathrm{~h})$.

In contrast, $5 \mathrm{~h}$ after GSPE administration, the levels of plasma NEFA decreased considerably. As plasma NEFA is a source for TAG synthesis in the liver and has an important role in stimulating hepatic VLDL production ${ }^{(19,25)}$, the reduction in plasma NEFA levels could be the mechanism hidden behind the repression of VLDL-TAG secretion induced by GSPE several hours after its administration. Moreover, concomitant to the decrease in plasma NEFA levels, GSPE treatment changed the expression pattern of $\mathrm{Cd} 36$ induced by lard alone. Hepatic Cd36 controls FA uptake by the liver, and its elevation in expression directly affects hepatic FA uptake, TAG storage and VLDL-TAG secretion ${ }^{(26)}$. Therefore, reduced NEFA levels in plasma, together with low levels of $\mathrm{Cd} 36$ expression, may result in decreased FA availability for TAG synthesis in the liver $5 \mathrm{~h}$ after GSPE administration, thus reducing VLDL-TAG secretion.

The described molecular mechanism by which GSPE represses hepatic TAG secretion involves the transcriptional activation of farnesoid $\mathrm{X}$ receptor ${ }^{(11)}$, overexpression of the nuclear receptor small heterodimer partner ${ }^{(10)}$ and repression of Srebp-1 $1^{(7,10,11)}$. We found no significant difference in the expression of small heterodimer partner or Srebp-1 after administering lard alone or lard +GSPE. Nevertheless, mRNA levels of Srebp-1 were always lower after GSPE treatment, and small heterodimer partner mRNA levels were higher $5 \mathrm{~h}$ after GSPE administration. Diet and hormones, primarily insulin, regulate the transcription of Srebp- ${ }^{(27)}$. In the present experiment, the animals received only a TAG overload, whereas in the experiments that describe the molecular mechanism of GSPE, the animals received a mixed diet. Thus, the differences in the diets, which in the present case reduced the expression of Srebp-1 in control animals (without GSPE), minimised the differences between animals treated with GSPE and those treated with vehicle.

In conclusion, the present results show that the oral intake of GSPE significantly blocked the increase in plasma TAG levels induced by lard oil ingestion. Both CM-rich and VLDLrich fractions contributed to the hypotriacylglycerolaemic action of GSPE, but their influence was time dependent. GSPE ingestion repressed VLDL-TAG secretion, but it did not increase TAG clearance. GSPE may block VLDL-TAG secretion because of the unavailability of FA for TAG synthesis, as a consequence of increasing FA oxidation shortly after administration and reducing plasma NEFA levels at later time periods. Overproduction of TAG-rich lipoproteins is characteristic of the dyslipidaemia in the metabolic syndrome and type 2 diabetes $^{(28,29)}$. Therefore, blockage of the TAG-rich lipoprotein secretion induced by PA may explain the association between dietary intake of flavonoids and certain foods rich in flavonoids and a reduced risk of death due to $\mathrm{CHD}$ and $\mathrm{CVD}^{(30)}$.

\section{Acknowledgements}

The authors thank Leticia Quesada for revising the manuscript. The present study was supported by grant number AGL 2008-00387/ALI from the Spanish Dirección General de Investigación del Ministerio de Educación y Ciéncia. L. A. is a member of MITOFOOD. The authors gratefully acknowledge Mercedes Heras and Niurka Llopiz for their technical assistance. All authors participated in the conception, design and interpretation of data. H. Q., S. D, D. P. and A. F.-I. performed sample extraction and analysis. H. Q. and C. B. were involved in writing and editing the paper. All authors reviewed the final manuscript. The authors declare no conflicts of interest.

\section{References}

1. Davidson M (2008) A review of the current status of the management of mixed dyslipidemia associated with diabetes mellitus and metabolic syndrome. Am J Cardiol 102, 19L-27L.

2. Cannon CP (2008) Mixed dyslipidemia, metabolic syndrome, diabetes mellitus, and cardiovascular disease: clinical implications. Am J Cardiol 102, 5L-9L

3. Nordestgaard BG, Langsted A \& Freiberg JJ (2009) Nonfasting hyperlipidemia and cardiovascular disease. Curr Drug Targets 10, 328-335.

4. Blade C, Arola L \& Salvado MJ (2010) Hypolipidemic effects of proanthocyanidins and their underlying biochemical and molecular mechanisms. Mol Nutr Food Res 54, 37-59.

5. Zern TL, Wood RJ, Greene C, et al. (2005) Grape polyphenols exert a cardioprotective effect in pre- and postmenopausal women by lowering plasma lipids and reducing oxidative stress. J Nutr 135, 1911-1917.

6. Del Bas JM, Fernandez-Larrea J, Blay M, et al. (2005) Grape seed procyanidins improve atherosclerotic risk index and induce liver CYP7A1 and SHP expression in healthy rats. FASEB J 19, 479-481.

7. Quesada H, del Bas JM, Pajuelo D, et al. (2009) Grape seed proanthocyanidins correct dyslipidemia associated with a high-fat diet in rats and repress genes controlling lipogenesis and VLDL assembling in liver. Int $J$ Obes (Lond) 33, $1007-1012$

8. Sugiyama H, Akazome Y, Shoji T, et al. (2007) Oligomeric procyanidins in apple polyphenol are main active components for inhibition of pancreatic lipase and triglyceride absorption. J Agric Food Chem 55, 4604-4609.

9. Vidal R, Hernandez-Vallejo S, Pauquai T, et al. (2005) Apple procyanidins decrease cholesterol esterification and lipoprotein secretion in Caco-2/TC7 enterocytes. J Lipid Res 46, $258-268$.

10. Del Bas JM, Ricketts ML, Baiges I, et al. (2008) Dietary procyanidins lower triglyceride levels signaling through the nuclear receptor small heterodimer partner. Mol Nutr Food Res 52, 1172-1181.

11. Del Bas JM, Ricketts ML, Vaque M, et al. (2009) Dietary procyanidins enhance transcriptional activity of bile acid-activated 
FXR in vitro and reduce triglyceridemia in vivo in a FXRdependent manner. Mol Nutr Food Res 53, 805-814.

12. Baiges I, Palmfeldt J, Blade C, et al. (2010) Lipogenesis is decreased by grape seed proanthocyanidins according to liver proteomics of rats fed a high fat diet. Mol Cell Proteomics 9, 1499-1513.

13. Schumaker VN \& Puppione DL (1986) Sequential flotation ultracentrifugation. Methods Enzymol 128, 155-170.

14. Havel RJ, Eder HA \& Bragdon JH (1955) The distribution and chemical composition of ultracentrifugally separated lipoproteins in human serum. $J$ Clin Invest 34, 1345-1353.

15. Qu S, Perdomo G, Su D, et al. (2007) Effects of apoA-V on HDL and VLDL metabolism in APOC3 transgenic mice. J Lipid Res 48, 1476-1487.

16. Fuster A, Oliver P, Sanchez J, et al. (2009) UCP1 and oxidative capacity of adipose tissue in adult ferrets (Mustela putorius furo). Comp Biochem Physiol A Mol Integr Physiol 153, 106-112.

17. Bieber LL, Abraham T \& Helmrath T (1972) A rapid spectrophotometric assay for carnitine palmitoyltransferase. Anal Biochem 50, 509-518.

18. Steg A, Wang W, Blanquicett C, et al. (2006) Multiple gene expression analyses in paraffin-embedded tissues by TaqMan low-density array: application to hedgehog and Wnt pathway analysis in ovarian endometrioid adenocarcinoma. J Mol Diagn 8, 76-83.

19. Julius U (2003) Influence of plasma free fatty acids on lipoprotein synthesis and diabetic dyslipidemia. Exp Clin Endocrinol Diabetes 111, 246-250.

20. Cohn JS (2008) Are we ready for a prospective study to investigate the role of chylomicrons in cardiovascular disease? Atheroscler Suppl 9, 15-18.
21. Gibbons GF, Wiggins D, Brown AM, et al. (2004) Synthesis and function of hepatic very-low-density lipoprotein. Biochem Soc Trans 32, 59-64.

22. Ginsberg HN \& Fisher EA (2009) The ever-expanding role of degradation in the regulation of apolipoprotein B metabolism. J Lipid Res 50, Suppl., S162-S166.

23. Olofsson SO, Bostrom P, Andersson L, et al. (2009) Lipid droplets as dynamic organelles connecting storage and efflux of lipids. Biochim Biophys Acta 1791, 448-458.

24. Soupene E \& Kuypers FA (2008) Mammalian long-chain acylCoA synthetases. Exp Biol Med (Maywood) 233, 507-521.

25. Duez H, Lamarche B, Valero R, et al. (2008) Both intestinal and hepatic lipoprotein production are stimulated by an acute elevation of plasma free fatty acids in humans Circulation 117, 2369-2376.

26. Koonen DP, Jacobs RL, Febbraio M, et al. (2007) Increased hepatic CD36 expression contributes to dyslipidemia associated with diet-induced obesity. Diabetes 56, 2863-2871.

27. Raghow R, Yellaturu C, Deng X, et al. (2008) SREBPs: the crossroads of physiological and pathological lipid homeostasis. Trends Endocrinol Metab 19, 65-73.

28. Adiels M, Olofsson SO, Taskinen MR, et al. (2008) Overproduction of very low-density lipoproteins is the hallmark of the dyslipidemia in the metabolic syndrome. Arterioscler Thromb Vasc Biol 28, 1225-1236.

29. Therond P (2009) Catabolism of lipoproteins and metabolic syndrome. Curr Opin Clin Nutr Metab Care 12, 366-371.

30. Mink PJ, Scrafford CG, Barraj LM, et al. (2007) Flavonoid intake and cardiovascular disease mortality: a prospective study in postmenopausal women. Am J Clin Nutr 85, 895-909. 